\title{
DERECHOS SOCIALES Y RECURSO DE PROTECCIÓN: ¿UNA RELACIÓN DIFÍCIL?
}

Rodrigo Bustos Bottai*

RESUMEN: En la actualidad, nuestro ordenamiento jurídico no contempla una protección judicial que garantice la concreción de los derechos sociales, mediante el Recurso de Protección. Lo anterior no es casual teniendo en cuenta los orígenes de la institucionalización de esta acción, los cuales han mantenido la resistencia de algunos sectores a incorporar los cambios producidos en la noción de derechos humanos, a lo que debemos sumar, la existencia de prejuicios sobre la efectividad real de proteger estos derechos. Dicho lo anterior, a continuación se describiran cada uno de estos prejuicios, sus orígenes, y se intentara refutar cada uno de los argumentos que han mantenido fuera de la cobertura del Recurso de Protección a los llamados derechos económicos, sociales y culturales.

\section{PALABRAS CLAVES: Derechos liberales - Derechos sociales - Recurso de Protección.}

ABSTRACT: Currently, our legal system does not consider giving judicial relief that warrants the concretion of social rights, through the "Recurso de Protección". The latter is not accidental taking into account the origins of this legal remedy's instutionalization, which have kept the resistance of some groups to incorporate the changes produced in the notion of human rights, to which we may add, the existence of prejudice on the real effectiveness of protecting these rights. With that said, we will describe each of these pre- judgments, its origins and we will try to refute every argument that has excluded economic social and cultural rights of legal coverage by the "Recurso de Protección".

KEY WORDS: Liberal rights - social rights - "Recurso de Protección” (judicial relief).

En el año 2006 se cumplieron treinta años desde que se implementó en nuestro país el Recurso de Protección. Esta acción procesal dirigida a dar protección a los derechos fundamentales consagrados en la Constitución de la República de 1980 (en adelante CPR) representó una novedad en el Derecho Constitucional chileno que, hasta entonces, sólo había contemplado el Recurso de Amparo o Habeas Corpus dirigido a proteger la libertad personal. Con el Acta Constitucional N ${ }^{0} 3$, y posteriormente en el seno de la Comisión de Estudios de la Nueva Constitución, se buscó establecer una acción que protegiera las demás garantías constitucionales $^{1}$. Sin embargo, este instrumento procesal se estableció sólo para resguardar

\footnotetext{
* Abogado, Facultad de Derecho, Universidad de Chile. Candidato a Doctor por la Universidad de Salamanca.

${ }^{1}$ En realidad, el primer antecedente de este instituto se encuentra en un proyecto de reforma constitucional presentado en 1972 por los parlamentarios señores Sergio Onofre Jarpa, Sergio Diez, Mario Arnello, Gustavo Lorca y Luis Undurraga. A través de dicha reforma se pretendía dotar a diversas garantías constitucionales de un instrumento rápido y eficaz que las protegiera pero, debido al contexto político de esa época, la iniciativa no prosperó y sólo pudo concretarse años más tarde. Para una revisión más detallada de los orígenes del Recurso de Protección y de su proceso de gestación Vid. SoTO KLoss, Eduardo. El Recurso de Protección. Santiago, Chile, Editorial Jurídica de Chile, pp.19-55.
} 
una parte de los derechos fundamentales, ya que el artículo 20 de la CPR enumera de manera taxativa los derechos que permiten interponer el Recurso de Protección ante la Corte de Apelaciones en caso de que se sufran actos u omisiones arbitrarios o ilegales que produzcan privación, perturbación o amenaza en su legítimo ejercicio. Los derechos mencionados por la citada disposición se enmarcan básicamente en los que vienen denominados derechos civiles y políticos mientras los derechos económicos, sociales y culturales quedaron afuera de la órbita de esta acción.

Se estableció una excepción para el derecho a vivir en un medio ambiente libre de contaminación, consagrado en el artículo $19 \mathrm{~N}^{\mathrm{o}} 8$ de la CPR. En este caso nos encontramos ante un derecho que se suele catalogar entre los derechos de tercera generación y que, por tanto, no tendría las mismas características que los más clásicos derechos de libertad. Precisamente por este motivo la utilización del Recurso de Protección en relación a este derecho se encuentra más restringida, y se establece para los casos en que se realice un acto u omisión ilegal -ya no es suficiente que sea arbitrario- y sólo cuando este pueda ser imputable a una autoridad o persona determinada ${ }^{2}$.

En la actualidad, la cuestión de si el Recurso de Protección debe garantizar sólo los derechos civiles y políticos o también los derechos sociales, vuelve a ser objeto de debate por la presentación de un proyecto de reforma constitucional que busca ampliar esta acción al derecho a la educación, del artículo 19 No 10 de la CPR, en los mismos términos establecidos para el derecho a vivir en un medio ambiente libre de contaminación ${ }^{3}$. Se trata de un paso importante aunque creemos que perfectamente se le podría otorgar al derecho de educación el mismo status que a los demás derechos protegidos por el Recurso de Protección, sin las limitaciones del derecho a vivir en un medio ambiente libre de contaminación $n^{4}$.

Respecto a las motivaciones que llevaron a los miembros de la Comisión de Estudios de la Nueva Constitución, éstas quedan graficadas de manera clara por las palabras del comisionado Jaime Guzmán, quien señaló que:

"es evidente que el Recurso de Protección no puede hacerse extensivo a derechos que, aunque reconocidos constitucionalmente, dependen para su debida satisfacción de la capacidad económica del Estado o de las potencialidades culturales de la población, como sucede con el derecho a la educación, a la salud, a la seguridad social y otros. Sólo puede establecerse un recurso judicial como el que analizamos, respecto de aquellos derechos cuyo ejercicio exige únicamente el que no se ha perturbado por la conducta ilegítima de la autoridad o de un particular, obstáculo que una vez removido por resolución judicial, basta para que el titular del derecho pueda disfrutar adecuadamente de él. De ahí la necesidad de enumerar

\footnotetext{
2 Antes de la reforma de la Ley No 20.050 de 26.08.2005 la posibilidad de interponer el Recurso de Protección respecto al derecho a vivir en un medio ambiente de libre de contaminación era aun más reducida ya que sólo podía tratarse de actos y no de omisiones y se exigía de manera copulativa que el acto fuera arbitrario e ilegal.

${ }^{3} \mathrm{Vid}$. Proyecto de Reforma constitucional que establece como deber del Estado velar por la calidad de la educación. Santiago, Chile, 6 de junio de 2006.

${ }^{4}$ Ibidem en el mismo sentido, Ruiz Tagle, Pablo y Correa, Sofía, "El Derecho a una Educación de Calidad". En: Anuario de Derechos Humanos, (3): 176, 2007.
} 
taxativamente los derechos respecto de los cuales se concede el mencionado recurso" $"$.

Esta posición fue compartida por la gran mayoría de los comisionados, lo que los llevó a determinar aquellos derechos que no debían comprenderse en la esfera del Recurso de Protección por requerir de prestaciones estatales para su realización ${ }^{6}$.

Cabe señalar que esta opción del constituyente de 1980 no es nueva. En muchos países la no realización de los derechos sociales se considera más una fatalidad que una verdadera vulneración de derechos esenciales del ser humano. A esto se agrega que, en el ámbito de la teoría de los derechos humanos, parte de la doctrina ha sostenido reiteradamente que los derechos sociales en realidad son normas programáticas o meras aspiraciones, defendiendo su inexigibilidad ante los poderes públicos, en especial respecto a los órganos legislativo y judicial ${ }^{7}$.

En mi opinión, los argumentos a favor de la falta de eficacia jurídica de los derechos sociales deben ser contextualizados en la evolución histórica de los derechos humanos. En un comienzo la noción de derechos humanos comprendía solo a los derechos civiles y fue con posterioridad que se fueron agregando a su concepto los derechos políticos y, todavía después, los derechos sociales. El proceso de incorporación de estos últimos derechos a los textos constitucionales fue paulatino pero, especialmente desde el fin de la Segunda Guerra Mundial, en la mayoría de los países occidentales las constituciones se contemplan enunciaciones más o menos extensas de derechos económicos y sociales.

La permanencia de posiciones defensoras de la inexigibilidad de los derechos sociales se deben a mi juicio, por un lado, a la resistencia de algunos sectores a incorporar los cambios producidos en la noción de derechos humanos y, por otro, a la existencia de algunos prejuicios sobre los derechos sociales que persisten hasta el día de hoy ${ }^{8}$. A continuación, abordaremos los principales argumentos de las posiciones que sostienen que los derechos sociales no pueden ser eficaces jurídicamente, intentaremos refutar esos argumentos y defenderemos la tesis de que el Recurso de Protección es no sólo perfectamente ampliable a los derechos sociales contemplados en nuestra Constitución, sino que se trata de una reforma pendiente y necesaria.

\footnotetext{
${ }^{5}$ Comisión De Estudios De La Nueva Constitución Política De La República, sesión 407, celebrada el miércoles 9 de agosto de 1978.

${ }^{6}$ Es pertinente mencionar que el comisionado Alejandro Silva Bascuñan señaló reiteradamente una posición distinta y sostuvo que el Recurso de Protección debía aplicarse a todos las garantías constitucionales. Comisión De Estudios De La Nueva Constitución Política De La República, sesiones 214 del martes 25 de mayo de 1976, 215 del miércoles 26 de mayo de 1976 y 216 del jueves 27 de mayo de 1976.

${ }^{7}$ Así, por ejemplo, el actual Presidente del Tribunal Constitucional ha señalado lo siguiente: “¿Por qué algunos derechos y libertades quedan omitidos? Porque son metas para el Estado cuyo cumplimiento depende de los medios disponibles al efecto, de manera que son expectativas que no forman derechos". CEA EGAÑA, José Luis, Tratado de la Constitución de 1980: características generales: garantias constitucionales, Santiago, Chile, Editorial Jurídica de Chile, 1988, p. 317.

${ }^{8}$ Se refieren expresamente a la existencia de prejuicios sobre los derechos sociales: LuCIANI, Máximo. "Sui diritti sociali”. En: Romboli, Roberto. La tutela dei diritti fondamentali alle Corti Costituzionali. G. Giapichelli, Torino, 1994, p. 80; PISARELLO, Gerardo. Los derechos sociales y sus garantias. Madrid, Editorial Trotta, 2007, p. 59.
} 


\section{Los derechos sociales son derechos positivos.}

Una de las afirmaciones jurídicas que se desprende de las citadas palabras del comisionado Jaime Guzmán es que los derechos civiles tendrían como contrapartida obligaciones negativas o de no hacer, mientras a los derechos sociales corresponderían obligaciones positivas o de hacer ${ }^{9}$. Según ese planteamiento, el Estado está impedido de matar a alguien, de vulnerar el derecho de propiedad o de negar injustificadamente el derecho a sufragio. Respecto a los derechos sociales la situación sería distinta. En el caso, por ejemplo, del derecho a la salud o del derecho a la educación, éstos se traducirían en la práctica en obligaciones positivas o de hacer del Estado hacia los individuos. De acuerdo a esa misma visión solo serían exigibles jurídicamente las abstenciones y, por tanto, los derechos civiles y políticos con lo cual el Recurso de Protección sólo puede caber para esta clase de derechos.

A mi juicio, nuevamente, esa posición debe enmarcarse en el contexto histórico en el que tuvieron origen las dos clases de derechos que estamos tratando. Las constituciones de las primeras versiones del Estado liberal de Derecho reconocían los derechos civiles y requerirían para su realización de la abstención del Estado. En el caso de los derechos económicos y sociales, en cambio, su origen está vinculado con la necesidad de disminuir las desigualdades existentes y de asegurar a todas las personas condiciones mínimas de vida, de lo cual se desprende que para asegurar esos derechos el Estado debe realizar acciones positivas. Sin embargo, al día de hoy la simple distinción entre derechos negativos y positivos ha perdido vigencia. Después de un mínimo estudio de los dos tipos de derechos se puede concluir fácilmente que los derechos civiles no implican solamente obligaciones negativas y los derechos sociales no se manifiestan sólo como obligaciones positivas o de hacer ${ }^{10}$.

Así, siendo más precisos, de lo que más propiamente cabría hablar en el caso de los derechos civiles y políticos es que las obligaciones principales por parte del Estado son obligaciones de no hacer, pero sin descuidar que también existen obligaciones secundarias o complementarias que se traducen en obligaciones positivas o de hacer. De esta manera, el derecho político al sufragio no sólo requiere que el Estado no entorpezca a los ciudadanos la posibilidad de expresar su posición política a través del voto (obligación principal negativa), sino que implica que el Estado debe cumplir con establecer y regular un sistema electoral que cumpla con la finalidad de que las elecciones se realicen en condiciones de igualdad y transparencia (obligaciones secundaria positivas). Otro ejemplo es el de las obligaciones estatales de no matar o no torturar (obligaciones principales negativas) ya que el Estado tiene también la obligación de establecer sistemas policiales y judiciales eficientes que contribuyan a evitar que esos delitos se produzcan, y a reparar las consecuencias de un eventual

\footnotetext{
9 BÖCKENFÖRDE, Ernst-Wolfgang. Escritos sobre derechos fundamentales. Baden-Baden, Nomos, 1993, pp. 76-78.

${ }^{10}$ De esta posición es CASCAjO CASTRO, para quien “(...) hoy no parece tan clara la supuesta separación entre sendas clases o tipos de derechos fundamentales. El carácter prestacional o participativo también puede ser un atributo de algunos de los llamados derechos clásicos de libertad individual. Por el contrario, este último elemento de defensa e iniciativa particular puede acompañar al sujeto titular de un derecho social, para percibir las oportunidades y prestaciones que un determinado sistema social le proporciona". CASCAjo CASTRO, José Luis. La tutela constitucional de los derechos sociales. Madrid, Centro de Estudios Constitucionales, 1988, p. 72. Vid., en el mismo sentido: LuCIANI, Massimo, op. cit. (n. 8), pp.96-97; ONIDA, Valerio. Eguaglianza e diritti sociali. Corte Costiturionale e principio di eguaglianza. Padova, CEDAM, 2001, p. 102.
} 
incumplimiento de las obligaciones de no afectar la vida humana y la integridad física (obligaciones secundarias positivas).

Lo anterior es aplicable también a los derechos sociales pues ellos no se traducen solamente para el Estado en obligaciones positivas sino que implican en muchas hipótesis obligaciones negativas ${ }^{11}$. Es el caso, por ejemplo, del derecho a la salud, el Estado no tiene solamente la obligación de prestar una adecuada atención de salud a los ciudadanos (obligación principal positiva), sino que también tiene el deber de no afectar este derecho en sus diversos aspectos mediante cualquier conducta que pudiera implicar prácticas nocivas a la salud (obligación secundaria negativa).

En esta línea, de descartar que los derechos civiles se asimilen en forma absoluta a obligaciones de no hacer y los derechos sociales a las de hacer, el Comité de Derechos Económicos, Sociales y Culturales propone un esquema que engloba ambas clases de derechos de manera conjunta. De acuerdo a este planteamiento, más que la simple distinción entre obligaciones negativas y positivas, cada derecho tendría diferentes niveles de protección ${ }^{12}$.

Así, existirían en primer lugar obligaciones de respetar, que se caracterizarían por el deber del Estado de no impedir el ejercicio de un derecho a los individuos. En un segundo nivel existirían obligaciones de proteger, las que implicarían evitar que terceras personas afecten o impidan el ejercicio de los derechos protegidos. Por último, existiría un tercer nivel constituido por las obligaciones de cumplir. En virtud de ellas, el Estado estaría obligado a garantizar el ejercicio del derecho en cuestión a quienes no puedan hacerlo por sí mismos. El esquema descrito se aplicaría tanto a los derechos civiles y políticos como a los derechos económicos, sociales y culturales, pero en este trabajo nos interesa analizar especialmente cuál es su aplicación en el caso de estos últimos.

El primer nivel de obligaciones que asumiría el Estado en relación a los derechos sociales parte del supuesto de que son los individuos los primeros que deben satisfacer sus propios derechos. Esta idea encuentra respaldo en la Declaración sobre el Derecho al Desarrollo, que identifica al individuo como el sujeto activo de todo desarrollo económico y social al señalar que "la persona humana es el sujeto central del desarrollo y debe ser el participante activo y el beneficiario del derecho al desarrollo"13. Por lo tanto, sería siempre el sujeto particular el que en primer lugar debe procurar, con sus propios medios, ejercitar sus derechos sociales. La importancia del rol de los individuos en la realización de sus propios derechos sociales ha sido especialmente desarrollada por la corriente del pluralismo jurídico, cuyo exponente principal es Georges Gurvitch. Este autor ha sostenido una postura antiestatal al plantear, fundamentalmente, que el Estado no es el único ente capaz de crear derecho ya que también lo pueden hacer los grupos de individuos organizados en una pluralidad de

\footnotetext{
${ }^{11}$ LuCAS Verdú, Pablo. Teoría general de las relaciones constitucionales. Madrid, Dykinson, 2000, p. 148.

12 Aunque la existencia de niveles de obligaciones respecto de derechos sociales ha sido reconocida en diversas observaciones generales, Vid., especialmente, Comité De Derechos Económicos, Sociales Y Culturales: Observación general № 12 (1999), El derecho a una alimentación adecuada, E/C.12/1999/5, Ginebra, 12 de mayo de 1999, párr. 15 y Observación general No 16 (2005), La igualdad de derechos del hombre y de la mijer al disfrute de los derechos económicos, sociales y culturales, E/C.12/2005/4, Ginebra, 11 de agosto de 2005, párr. 17.

${ }^{13}$ Asamblea General De Las Naciones Unidas: Declaración sobre Derecho al Desarrollo, Resolución 41/128, de 4 de diciembre de 1986, artículo 2.1 .
} 
asociaciones que varían dependiendo de los distintos ámbitos sociales, y que deben ejercer en primer lugar sus derechos sociales ${ }^{14}$.

El segundo nivel de obligaciones serían las de proteger. Ellas exigirían la tutela por parte del Estado de la libertad de los individuos de ejercer sus derechos con sus propios recursos sin ser afectados por terceras personas. Este nivel de obligaciones tiene relación con el deber de los individuos particulares de respetar los derechos humanos, en lo se ha llamado por la doctrina efecto terciario o Drittwirkung ${ }^{15}$. En el Pacto Internacional de Derechos Económicos, Sociales y Culturales (en adelante, PIDESC) existen varios pasajes que hacen referencia a la posibilidad que sean los sujetos individuales los que afecten los derechos contenidos en su texto ${ }^{16}$. Este nivel de obligaciones estatales tiene especial relevancia en el ámbito de las relaciones laborales, ya que el Derecho del Trabajo interviene, fundamentalmente, en relaciones entre privados ${ }^{17}$. Además, con el creciente proceso de globalización económica el efecto horizontal de los derechos humanos tiene cada vez más relevancia, un ejemplo de ello, es que se reconoce que las empresas trasnacionales pueden violar los derechos humanos inclusive más que los mismos gobiernos. Ha sido en este nuevo contexto que, en el año 2003, se adoptaron en el marco de las Naciones Unidas las Normas de la ONU sobre las Responsabilidades de las Empresas Transnacionales y Otras Empresas Comerciales en la Esfera de los Derechos Humanos. Esta declaración ha sido suscrita de manera voluntaria por empresas de todos los países, teniendo especial importancia en el ámbito de los derechos sociales por sus exigencias en materia de derechos laborales y de protección al medio ambiente.

En el caso de las obligaciones de cumplir, correspondientes al tercer nivel de obligaciones, ellas requieren para su cumplimiento un rol más activo por parte del Estado. Sin embargo, de la necesidad de adoptar medidas no se desprende que ellas se traduzcan necesariamente en desembolsos de recursos económicos.

De esta forma, todos los derechos fundamentales deben ser considerados como un todo, constituido por un haz de obligaciones y posiciones diversas que no pueden ser vistas en forma unívoca. Es relevante destacar que esta interpretación de las obligaciones generadas por el PIDESC es de plena aplicación en nuestro país en virtud del artículo 5 inciso segundo de la $\mathrm{CPR}^{18}$. Por todo lo anterior, no compartimos el postulado basado en la distinción derechos

\footnotetext{
${ }^{14}$ BobBIO, Norberto. "Gurvitch y los derechos sociales". En su: El tiempo de los derechos, Madrid, Editorial Sistema, 1991, pp. 30 y 34.

${ }^{15}$ Sobre la "Drittwirkung" o efecto horizontal de los derechos humanos Vid. AlEXY, Robert. Teoría de los Derechos Fundamentales. Madrid, Centro de Estudios Constitucionales, 2002, pp. 506-524; y, García TORRES, Jesús y JimÉnEZ-Blanco, Antonio. Derechos fundamentales y relaciones entre particulares. Madrid, Civitas, 1986, pp. 149.

${ }^{16}$ Así lo hace, por ejemplo, el artículo 5 el cual señala que "ninguna disposición del presente Pacto podrá ser interpretada en el sentido de reconocer derecho alguno a un Estado, grupo, individuo para emprender actividades o realizar actos encaminados a la destrucción de cualquiera de los derechos o libertades reconocidos en el Pacto, o a su limitación en medida mayor que la prevista en él'.

${ }_{17}$ Cascajo Castro, José Luis, op. cit. (n. 10), p.68.

${ }^{18}$ No es este el lugar para profundizar acerca de la jerarquía de los tratados internacionales de derechos humanos en nuestro ordenamiento jurídico siendo, además, que existe una extensa bibliografía sobre el tema. Es en este momento suficiente señalar que partimos del presupuesto que se trata de normas jurídicamente obligatorias. Respecto a la jerarquía de los tratados de derechos humanos suscritos por Chile Vid., en especial: Infante, María Teresa. Los Tratados en el Derecho Interno Chileno: "El Efecto de la Reforma Constitucional de 1989 visto por la jurisprudencia". Revista Chilena de Derecho, 23(2 y 3): 277-297, 1996; y, Nogueira, Humberto. "Los Tratados Internacionales en el Ordenamiento Jurídico Chileno". Revista Chilena de Derecho, 23(2 y 3): 341-380, 1996.
} 
negativos/positivos, según el cual los derechos sociales no pueden ser exigibles y deben quedar afuera del ámbito del Recurso de Protección.

2. Los derechos sociales dependen de la disponibilidad económica.

Otro de los argumentos más frecuentes contra la eficacia jurídica de los derechos sociales es el de la denominada disponibilidad económica. Esta idea surge de la premisa de que los derechos económicos, sociales y culturales, a diferencia de los derechos civiles y políticos, requieren para su realización del desembolso de recursos económicos. Como consecuencia de lo anterior, los derechos sociales podrían ser relativizados y tendrían menor eficacia jurídica ya que dependerían de la riqueza existente en cada país en un momento histórico determinado, en tanto los gobiernos siempre se encontrarían obligados a respetar los derechos civiles y políticos ${ }^{19}$. Esta idea ha sido denominada en la doctrina alemana como reserva de lo posible.

En Chile, esta concepción encontró plena acogida durante la elaboración del actual texto constitucional. Como ya mencionamos anteriormente los derechos sociales no están tutelados por el recurso de protección, siendo el principal argumento esgrimido al interior de la Comisión de Estudios de la nueva Constitución que la realización de estos derechos depende de la capacidad económica del Estado en un momento determinado y, por tanto, no pueden ser exigidos a través de una acción judicial. No obstante, cabe que nos preguntemos si el postulado de que los derechos sociales no tienen eficacia jurídica con razón de su coste económico tiene o no una sólida base argumentativa. De inmediato corresponde decir que no se puede desconocer que algunos derechos socioeconómicos requieren de importantes desembolsos monetarios y que éstos, en algunos casos, pueden asumir dimensiones relevantes. Pero, ¿acaso para asegurar la garantía del debido proceso, contenida en el artículo $19 \mathrm{~N}^{\circ} 3$ de la CPR, no se requiere la destinación de partidas del presupuesto que permitan la existencia de tribunales, jueces y, en general, de todo el aparato judicial funcionando de manera adecuada? $¿$ ¿No necesita el derecho al sufragio que el Estado gaste recursos públicos para asegurar que los procesos electorales se desarrollen de manera eficiente y transparente? Nos parece claro que respecto a muchos derechos civiles y políticos se requiere, como en el caso de los derechos económicos, sociales y culturales, de desembolsos de recursos económicos y que, sin embargo, nadie desconoce que se pueda recurrir a los tribunales de justicia o al Tribunal Constitucional cuando han sido violados ${ }^{20}$. Por lo mismo, creemos que los planteamientos que parten de la idea de que existirían libertades civiles baratas y derechos sociales caros están más fundados en prejuicios que en razones de técnica jurídica.

\footnotetext{
${ }^{19}$ Así, De CASTRO CID, aunque señala que los derechos sociales son verdaderos derechos imprescindibles para la defensa de la dignidad humana, señala reiteradamente que su operatividad jurídica depende de las condiciones sociales, económicas y políticas presentes en cada país. DE CASTRO CID, Benito. Los derechos económicos, sociales y culturales: análisis a la luz de la teoría general de los derechos humanos. León, Universidad de León, 1993, pp. 167-181. En el mismo sentido Vid. MARTíNEZ EsTAY, José. Jurisprudencia Constitucional Española sobre Derechos Sociales. Barcelona, Cedecs Editorial, 1997, pp. 103-106.

${ }^{20}$ Son muchos los autores que han sostenido la inexactitud de las posiciones que plantean el problema del costo económico solo para la realización de los derechos sociales. Vid., entre otros: Liebenberg, Sandra. Adjudicación de Derechos Sociales en la Constitución de Transformación Social de Sudáfrica. Anuario de Derechos Humanos, (2): 54, 2006; y, Luciani, Máximo. op. cit. (n. 8), p. 100.
} 
Como vimos anteriormente, para la realización de los derechos sociales no se requiere sólo el cumplimiento de obligaciones positivas sino también omisiones. Incluso, dentro de las acciones positivas necesarias para asegurar los derechos sociales, múltiples medidas no implican casi desembolsos de recursos económicos, como ocurre con la aprobación de nuevas leyes, el establecimiento de marcos regulatorios o la regulación de un servicio público, sea éste administrado por el Estado o por privados ${ }^{21}$.

Entre los que han defendido la posición de que todos los derechos implican desembolsos económicos para su adecuada realización, destaca el aporte de los juristas norteamericanos Holmes y Sunstein. Dichos autores han mostrado a través de numerosos ejemplos concretos que los argumentos de quienes defienden la imposibilidad de exigir jurídicamente los derechos sociales por su elevado costo están, en el caso de los Estados Unidos de Norteamérica, motivados simplemente por prejuicios ideológicos que no se corresponden a la realidad. Han evidenciado, por ejemplo, como para asegurar el derecho de propiedad en los Estados Unidos cada año se establece un gasto público enormemente elevado. O acaso, cla existencia de los cuerpos de policía y de los tribunales de justicia no busca en gran medida prevenir y reprimir delitos a la propiedad como el hurto y el robo? Y la propiedad de los bienes inmuebles, ¿no requiere de un complejo y costoso sistema de registro? Sin duda que sí, y no podemos olvidar que la propiedad intelectual también está regulada y tiene sistemas de protección que requieren desembolsos de recursos públicos. A lo anterior se agrega, además, el gasto público en política de defensa que tiene como objetivo proteger bienes como la vida, la integridad física, y así también, la propiedad de los habitantes de un Estado. Todas las anteriores son solo algunas muestras de cómo un clásico derecho liberal necesita para su adecuado desarrollo del gasto público del Estado ${ }^{22}$.

Insistimos en que es un hecho evidente que la realización de los derechos no requiere solamente de su reconocimiento jurídico y del establecimiento de mecanismos de tutela sino también de muchos otros factores y, entre ellos, la situación económica de cada país. Por los mismo, por más que en muchos países de África u otros extremadamente pobres se hayan establecidos extensas listas de derechos, su efectividad es muy limitada, entre otras cosas, por la fragilidad de su aparato estatal y la inexistencia de recursos económicos que permitan adoptar medidas para su realización. Pero en esos países las deficiencias mencionadas y los problemas de eficacia de los derechos suelen producirse para todas las clases de derechos y no sólo para los económicos, sociales y culturales. Muchas veces incluso las violaciones a los derechos humanos a gran escala afectan de manera conjunta diversos derechos con contenido muy disímil.

\footnotetext{
${ }^{21}$ Según Robert ALEXY “el derecho a prestaciones es la contrapartida exacta del concepto del derecho de defensa, bajo el que cae todo derecho a un acción negativa, es decir, a una omisión por parte del Estado. La escala de las acciones positivas del Estado que pueden ser objeto de un derecho a prestaciones se extiende desde la protección del ciudadano frente a otros ciudadanos a través de normas del derecho penal, pasando por el dictado de normas de organización y procedimiento, hasta prestaciones en dinero y bienes". AleXY, Robert. op. cit. (n. 15), p. 427. Vid. en este mismo sentido PISARELLO, Gerardo. op. cit. (n. 8)., p. 61; Nowak, Manfred. El Pacto Internacional de Derechos Civiles y Políticos. En: GÓMEZ IsA, Felipe (director). La protección internacional de los derechos humanos en los albores del siglo XXI. Bilbao, Universidad de Deusto, 2004, p. 171; ABRAMOVICH, Víctor y CourTIS, Christian. Los derechos sociales como derechos exigibles. Madrid, Editorial Trotta, 2002, pp. 33-37.

22 Todos los ejemplos mencionados y muchos más se encuentran en la citada obra de Holmes y Sunstein: The cost of rigths. Sobre específicamente los costos que implica la protección del derecho de propiedad ver especialmente: HoLMES, Stephen y SunSTEIN, Cass. The cost of rights: why liberty depends on taxes. New York, W. W. Norton, 1999, pp. 255.
} 
Dicho lo anterior, queda claro que nuestro propósito no es desconocer que la realización de los derechos sociales requiere frecuentemente de un alto nivel de gasto público. El planteamiento expuesto es otro y consiste básicamente en liberar los debates sobre la efectividad de los derechos de argumentos que revelan solamente una determinada posición ideológica. Entendemos que debido a limitaciones de recursos en una sociedad democrática se pueda priorizar la realización de unos derechos sobre otros, pero ello debe señalarse con claridad y no afirmarse que unos derechos pueden exigirse a los poderes públicos porque requieren simplemente de su no intervención mientras otros derechos deben quedar al arbitrio del legislador ya que implican decisiones presupuestarias. En los debates acerca de los derechos muchas veces se convierten informaciones no contrastadas en hechos evidentes de los que deben derivarse como lógicas consecuencias determinadas decisiones políticas. Una de estas situaciones se produce, a mi juicio, con la afirmación de que el Recurso de Protección no puede resguardar los derechos sociales debido a su elevado coste económico. Como hemos venido argumentando, todos los derechos implican gastos de dinero sin que ello descarte de manera automática su exigibilidad jurisdiccional.

3. La discrecionalidad del legislador en la regulación de los derechos sociales.

Otra idea muy asentada en la doctrina contraria a la exigibilidad jurídica de los derechos sociales y a su obligatoriedad para el legislador, es que ellas implicarían afectar la discrecionalidad de la que debe gozar el legislador en estas materias como poder legitimado a través de la voluntad soberana. Uno de los autores que expresa visiblemente esta opinión es BÖCKENFÖRDE que, si bien no duda en afirmar que la realización de los derechos sociales es necesaria para asegurar la libertad individual, considera que no son justiciables. El raciocinio de este autor se basa principalmente en el presupuesto -ya rebatido más arriba- de que los derechos socioeconómicos son derechos de prestación mientras que los civiles y políticos requieren abstenciones. A lo anterior añade que las prestaciones necesarias para asegurar los derechos sociales deben ser concretadas por el legislador en el marco de la división de poderes propia de un Estado de Derecho. A juicio de Böckenförde, "si se encomendara al juez la aplicación inmediata de derechos fundamentales sociales mediante la concesión de pretensiones jurídicas concretas y reclamables, debería entonces desempeñar al mismo tiempo el papel del legislador y del administrador"23.

La posición de que los derechos sociales son derechos de configuración legal y no auténticos derechos constitucionales ha sido muy difundida en el ámbito de la Filosofía del Derecho y del Derecho Constitucional. Sin ir más lejos, en la teoría de la justicia de Rawls los derechos sociales quedan residenciados en el poder legislativo debido a que, según este connotado jurista norteamericano, los derechos sociales implicarían, con mayor intensidad que en el caso de los derechos civiles y políticos, la necesidad de optar por diferentes visiones políticas ${ }^{24}$. Se trata, sin embargo, de una argumentación coherente con una visión del Estado de Derecho alejada de la utilizada en este trabajo. No es este el lugar para profundizar en esta

\footnotetext{
${ }^{23}$ BÖCKENFÖRDE, Ernst-Wolfgang. op. cit. (n. 9)., pp. 77-78.

${ }^{24}$ RAWLs, John. A Theory of Justice (revised edition). Massachussets, Cambridge, The Belknapp Press of Harvard University Press, 1999, p. 174.
} 
cuestión pero nos parece oportuno mencionar algunas consideraciones acerca de los orígenes del concepto de Estado de Derecho. Es sabido que las dos revoluciones liberales de fines del siglo XVIII siguieron en diversos aspectos caminos diferentes. Uno de estos aspectos fue el de la versión de Estado de Derecho que implementaron. Mientras en la Francia post revolucionaria se adoptó la forma de Estado de Derecho legislativo liberal con un poder legislativo soberano y casi sin limitaciones, en los Estados Unidos de Norteamérica se impuso una opción diferente: el Estado constitucional de Derecho.

En el caso de la Revolución francesa se buscaba poner fin al poder absoluto del soberano erigiendo, de manera incontrarrestada, al legislador como representante de la voluntad soberana. De esta manera, en Francia -y en las posteriores constituciones europeasel texto constitucional sólo establecía directrices hacía el órgano legislativo, que era visualizado como un poder omnipotente y las mayorías democráticas del momento no podían ser limitadas de manera alguna. Al otro lado del Atlántico se decidió que incluso el Poder Legislativo debía tener límites y que estos debían ser establecidos por una Constitución legitimada por un consenso ciudadano, que se erigía como norma suprema que obligaba a todos los poderes del Estado.

No fue hasta el período de entre guerras del siglo XX, y sobretodo después de la Segunda Guerra Mundial, que los ordenamientos jurídicos europeos incorporarían el principio de supremacía constitucional y el régimen de Estado constitucional de Derecho. En especial, fue la experiencia del nazismo y del fascismo en los países europeos lo que indujo a los nuevos constituyentes a limitar el poder de las mayorías ${ }^{25}$. En América Latina este principio fue recepcionado en las constituciones aprobadas una vez finalizadas las dictaduras de los años setenta y ochenta del siglo pasado.

Esta transformación en la noción de Estado de Derecho tiene diversas consecuencias; entre ellas, la forma en que se concibe la división de poderes. En la época en que se forjó la noción de Estado de Derecho en Europa la división de poderes era considerada un dogma absoluto porque se pretendía evitar la existencia de un poder ejecutivo excesivamente poderoso. Ninguno de los tres tradicionales poderes del Estado -ejecutivo, legislativo y judicial- podía invadir las prerrogativas que les correspondían a los otros. En cambio, con la noción de Estado constitucional de Derecho, recogida actualmente en la mayoría de las constituciones, se asume que los diversos órganos del Estado se controlan unos a otros y entran en continuas relaciones recíprocas ${ }^{26}$. En este contexto el juez deja de ser la voz. muda que pronuncia las palabras de la ley y con la Constitución en la mano puede reinterpretar las leyes e incluso, en muchos ordenamientos jurídicos, invalidarlas por su inconformidad con el texto constitucional.

\footnotetext{
${ }_{25}$ Ferrajoli, Luigi. "Democracia constitucional". En: COURTIS, Christian (compilador). Desde otra mirada. Buenos Aires, Eudeba, 2001, pp. 258-262.

${ }^{26}$ Esto es muy bien expresado por PRIETO SANCHís cuando, al referirse al actual noción de Constituciones, señala que "ya no permite concebir las relaciones entre legislador y juez, entre política y justicia, en los términos estrictos y formalmente escalonados propios del Estado de Derecho decimonónico, sino que obliga a una concepción más compleja y, si se quiere, más cooperativa de las fuentes del Derecho, donde un principio de equilibrio y flexibilidad venga a moderar la antaño rígida subordinación”. PRIETO SANCHís, Luis. "Los derechos sociales y el principio de igualdad sustancial". En: AÑON ROIG, María José (ed.). La universalidad de los derechos sociales: el reto de la inmigración. Valencia, Tirant Lo Blanch, 2004, p. 167.
} 
No obstante lo anteriormente argumentado, algunos siguen sosteniendo respecto a los derechos sociales que el legislador es el más indicado para definir con absoluta libertad su contenido y plazos de actuación. Al tratarse del órgano que posee legitimidad democrática por voluntad de la ciudadanía le correspondería de manera exclusiva regular estas cuestiones que, entre otras cosas, implican significativas decisiones presupuestarias. De acuerdo a esta posición los tribunales de justicia no deberían inmiscuirse en la protección de derechos sociales a menos que existan normas legales desarrolladas por parte del legislador. Al respecto nos cabe afirmar que, si bien comprendemos el temor de que se judicialicen en exceso las políticas sociales, creemos que el poder judicial puede tener un rol importante en materia de derechos sociales. Sabemos que es inimaginable que en causas judiciales específicas se pueda intervenir en la planificación de áreas tan relevantes como la salud, la educación y, en general, las que tienen que ver con los derechos sociales. Tampoco desconocemos el riesgo que se produciría para la equidad del sistema político si el poder judicial interviniera en algunos casos de una forma y en otros de una manera distinta. No obstante, se ha demostrado en la práctica que si los órganos jurisdiccionales son provocados de manera adecuada pueden cumplir un rol muy relevante en la protección de los derechos sociales que, incluso, pueden derivar en cambios a nivel de la Administración o del Poder legislativo ${ }^{27}$. En nuestro concepto los tribunales no pueden desentenderse del incumplimiento flagrante de preceptos constitucionales, ya sea que se trate de derechos civiles y políticos o de derechos económicos, sociales y culturales. Como bien lo manifiesta Pisarello adoptar otra postura implicaría "otorgar cobertura a la impunidad de los poderes estatales en la vulneración de los derechos sociales y, por lo tanto, en la erosión de los propios presupuestos materiales que sostienen y aseguran la subsistencia en el tiempo del proceso democrático mismo"28.

La fórmula de Estado constitucional de Derecho tiene, también, como pilar el principio de supremacía constitucional, el cual implica que los preceptos establecidos en las constituciones no son simples orientaciones para el legislador sino que obligan jurídicamente a dicho órgano como a los demás poderes del Estado. Como señala Loewenstein, para que un Estado pueda tener el calificativo de constitucional debe contar con una Constitución normativa, esto es, un texto jurídico que regule el proceso político real ${ }^{29}$.

En el caso de Chile, el principio de supremacía constitucional fue recogido en el artículo 6 del actual texto constitucional y, en especial, en su inciso primero que dispone que "los órganos del Estado deben someter su acción a la Constitución y a las normas dictadas conforme a ella, y garantizar el orden institucional de la República". Dicha disposición se traduce a nuestro entender en que todos los preceptos constitucionales -incluyendo los que consagran derechos sociales- establecen obligaciones a los poderes públicos y que, por tanto, no cuentan con discrecionalidad absoluta en su regulación. En última instancia, queremos hacernos eco de las palabras de Ferrajoli, según el cual los derechos sociales fundamentales

\footnotetext{
${ }^{27}$ PISARELlO, Gerardo. Derechos sociales, democracia e inmigración en el constitucionalismo español: del originalismo a una interpretación sistemática evolutiva. En: AÑON ROIG, María José (ed.). La universalidad de los derechos sociales: el reto de la inmigración. Valencia, Tirant Lo Blanch, 2004, p. 65; y, ABRAMOVICH, Víctor y CouRTIS, Christian. op. cit. (n. 21 )., p. 44.

${ }^{28}$ PisARELLO, Gerardo. op. cit. (n. 27), p. 63.

${ }^{29} \mathrm{La}$ Constitución normativa se diferenciaría de la Constitución nominal, que sería aquella en la que el proceso político transcurre al margen de lo prescrito y de la Constitución semántica, esto es, la que se traduce meramente en un sistema de dominación. Loewenstein, Kart. Teoría de la Constitución. Barcelona, Ariel, 1976, pp. 217 y ss.
} 
están, al igual que los derechos civiles y políticos, en la esfera de lo indecidible ${ }^{30}$. Existirían cuestiones que el constituyente ha dejado zanjadas y que el órgano legislativo puede desarrollar de diversas maneras pero de ningún modo puede afectar a su esencia. Los derechos sociales serían, en nuestra opinión, una de estas cuestiones y precisamente por ello deberían contar con mecanismos que resguarden su ejercicio como, por ejemplo, el Recurso de Protección.

4. Inexistencia de mecanismos de garantía y problemas de técnica jurídica.

Por último, otro de los principales argumentos de quienes sostienen que los derechos sociales son meros planteamientos programáticos es que generalmente no existen los mecanismos judiciales adecuados para poder exigir el cumplimiento de estos derechos ante los tribunales de justicia. Respecto a ese planteamiento debe admitirse que es cierto que, tanto en los tratados internacionales como en las constituciones nacionales, existe un desequilibrio respecto de las garantías contempladas para asegurar el cumplimiento de los derechos civiles, por un lado, y los derechos sociales, por otro. Es evidente también que en la mayoría de los textos constitucionales esta diferencia ha redundado en una menor protección de los derechos sociales. Sin embargo, la inexistencia de instrumentos procesales concretos no es un argumento suficiente para afirmar que los derechos sociales no son ni pueden ser justiciables. $\mathrm{Si}$ bien efectivamente a menudo no existen en los ordenamientos jurídicos nacionales mecanismos adecuados para proteger los derechos sociales reconocidos, dichos mecanismos pueden ser creados e incluso el legislador puede estar obligado a hacerlo ${ }^{31}$. En relación al ordenamiento jurídico chileno, nos parece que no es sostenible afirmar que los derechos sociales no son ni pueden llegar a ser exigibles jurídicamente porque el Recurso de Protección expresamente no los tutela. Como dice Ferrajoli, "lo que no puede consentirse es la falacia realista de la reducción del derecho al hecho y la determinista de la identificación de lo que acontece con lo que no puede dejar de acontecer" 32 .

Ahora bien, el problema persiste si los derechos sociales no pueden ser garantizados jurisdiccionalmente debido a elementos intrínsecos a su naturaleza jurídica. Esta es la posición de un sector de la doctrina que señala que los derechos sociales adolecen de ser excesivamente indeterminados en cuanto a su contenido como respecto a los sujetos pasivos ${ }^{33}$. Lo anterior generaría dificultades técnicas insoslayables en la elaboración de las garantías de los derechos con un contenido socioeconómico y explicaría el hecho de que en múltiples constituciones los derechos económicos y sociales aparecen reconocidos como meros principios programáticos. La posibilidad de garantizar los derechos sociales sería por tanto muy diferente a la de los derechos civiles que siempre tendrían plena efectividad de inmediato. Así, mientras los segundos constituirían estados, esto es, derechos perfectos desde un punto de vista jurídico, los derechos sociales serían procesos que se encontrarían en una etapa intermedia en la que, estando reconocidos, aún no serían justiciables pero pueden llegar a serlo de manera progresiva.

\footnotetext{
${ }^{30}$ Ferrajoli, Luigi. Derechos y garantías. La ley del más débil. Madrid, Editorial Trotta, 1999, pp. 23-24.

31 Abramovich, Víctor y COURTis, Christian. op. cit. (n. 21), p. 40.

32 Ferrajoli, Luigi. Derechos y garantías. La ley del más débil. Madrid, Editorial Trotta, 1999, p. 65.

33 Fernández-Miranda CampoAmor, Alfonso. El Estado social. Revista Española de Derecho Constitucional, 69(23): 160-163, septiembre/diciembre 2003.
} 
Según estos planteamientos derechos como el derecho a la salud o el derecho a la vivienda serían vagos e indeterminados en cuanto a su contenido y a las obligaciones que generan. Sin embargo, compartimos la opinión de aquellos que, si bien admiten que lo anterior es en parte cierto, sostienen que la indeterminación no es exclusiva de los derechos sociales y es más bien consustancial al lenguaje en general, al lenguaje jurídico en particular y, más especialmente aún, al discurso de los derechos ${ }^{34}$.

Expliquemos lo anterior con un ejemplo. En el caso de un derecho civil tan importante como el derecho a la vida, ¿podemos afirmar que se trata de un derecho que implica la abolición de la pena de muerte? ¿Ese simple enunciado general conlleva la prohibición de prácticas abortivas? ¿Permite o impide la eutanasia? Las respuestas a estas interrogantes no son uniformes e incluso dentro de las mismas sociedades occidentales las soluciones propuestas han sido diversas. Lo mismo ocurre con otros derechos civiles y políticos que en las constituciones y tratados de derechos humanos están redactados en términos muy generales y dan lugar a complejas cuestiones.

Otros autores, más que objetar la indeterminación del contenido de los derechos sociales plantean que en esta clase de derechos el problema sería la indeterminación del sujeto pasivo. Este ha sido en especial un planteamiento formulado por el economista austriaco F. Hayek, uno de los más acérrimos opositores a la idea de los derechos sociales como derechos jurídicamente exigibles. Su principal fundamento ha sido que, mientras los derechos individuales pueden ser exigidos a personas u organizaciones determinadas, los derechos sociales tendrían como sujeto pasivo a un difuso concepto de sociedad ${ }^{35}$. Por ese motivo, los derechos sociales no tendrían el carácter de derechos sino más bien la naturaleza de simples aspiraciones, posibilidades o idealidades cuya satisfacción, por tanto, no resulta exigible. Este autor comparte con Kelsen la posición de que un derecho que no tiene la correspondiente protección jurídica no lo es en sentido estricto y llega a afirmar que referirse a meras aspiraciones sociales como derechos degrada el verdadero contenido de este concepto ${ }^{36}$. Recordamos que para Kelsen "la esencia del derecho subjetivo, cuando es más que el mero reflejo de una obligación jurídica, se encuentra en el hecho de que una norma jurídica otorga a un individuo el poder jurídico de reclamar, mediante una acción, por el incumplimiento de la obligación" 37 .

Otros autores, como L. Prieto Sanchís, señalan que los derechos sociales independientemente de su estructura lingüística tienen naturaleza jurídica y participan de la fuerza propia de las normas constitucionales ${ }^{38}$. A nuestro juicio el que un derecho no tenga los correspondientes medios de tutela jurisdiccional puede eventualmente dificultar su realización pero no significa que un derecho deje de serlo; es decir, no modifica su naturaleza jurídica. El prestigioso jurista italiano Ferrajoli es muy claro en este aspecto al señalar que "el nexo entre expectativas y garantías no es de naturaleza empírica sino normativa, que puede ser contradicho por la existencia de las primeras y por la inexistencia de las segundas; y que, por

\footnotetext{
${ }^{34}$ PISARELLO, Gerardo. Los derechos sociales y sus garantías. (n. 8), pp. 67-72.

${ }^{35}$ HAYEK, Friedrich. Derecho, Legislación y Libertad, Vol. 2, El espejismo de la justicia social. Madrid, Unión Editorial, 1979, pp. 175-176.

${ }^{36}$ Idem. p. 180.

${ }^{37}$ KeLSEN, Hans. Teoría pura del derecho. México, Editorial Porrúa, 2005, p. 148.

${ }^{38}$ PRIETO SANCHÍs, Luis. op. cit. (n. 26), pp. 145-148.
} 
consiguiente, la ausencia de garantías debe ser considerada como una indebida laguna que los poderes públicos internos e internacionales tienen la obligación de colmar (...)"39.

Sobre la justiciabilidad de los derechos sociales Alexy, al presentar su modelo de derechos sociales fundamentales, recuerda acertadamente que "los problemas de justiciabilidad que surgen en el marco de este modelo no se diferencian básicamente de los que se presentan en los derechos fundamentales tradicionales" 40 . Con base a lo anterior podemos decir que, a nuestro entender, la diversa regulación establecida para los derechos sociales en la Constitución chilena no obedece a ningún motivo técnico sino más bien a la voluntad constituyente.

El Comité de Derechos Económicos, Sociales y Culturales de Naciones Unidas ha señalado al respecto que "aunque sea necesario tener en cuenta el planteamiento general de cada uno de los sistemas jurídicos, no hay ningún derecho reconocido en el Pacto que no se pueda considerar que posee en la gran mayoría de los sistemas algunas dimensiones significativas, por lo menos, de justiciabilidad" ${ }^{41}$. Es pertinente señalar que el Comité ha sido especialmente crítico respecto a la falta de justiciabilidad que tienen los derechos sociales ante los tribunales chilenos ${ }^{42}$.

Por lo anterior, nos parece que la ampliación del Recurso de Protección al derecho a la educación es un paso importante en la idea de romper con la dicotomía entre derechos exigibles y normas programáticas pero se debe seguir avanzando en la dirección de que todos los derechos fundamentales sean susceptibles de protección por esta acción constitucional ${ }^{43}$. No existe ninguna argumentación que a nuestro parecer pueda seguir sustentando el hecho que ante violaciones a derechos sociales como, por ejemplo, el derecho a la protección de la salud y el derecho a la seguridad social regulados respectivamente en los artículos $19 \mathrm{~N}^{\circ} 9$ y 19 $\mathrm{N}^{\mathrm{o}} 18$ no pueda también interponerse la acción de protección.

\section{REFERENCIAS BIBLIOGRAFICAS}

ABramovich, Víctor y COURTIS, Christian. Los derechos sociales como derechos exigibles. Madrid, Editorial Trotta, 2002.

\footnotetext{
${ }^{39}$ FERRAJOLI, Luigi. Derechos y garantías. La ley del más débil. Madrid, Editorial Trotta, 1999, p. 63.

40 ALEXY, Robert. op. cit., p. 427.

${ }^{41}$ COMITÉ DE DERECHOS ECONÓMICOS, SOCIALES Y CULTURALES: Observación general No 9 (1998), La aplicación interna del Pacto, E/C.12/1998/24, Ginebra, 3 de diciembre de 1998, párr. 10.

42 Así, en las conclusiones al último informe presentado por el Estado de Chile el Comité de DESC sugirió que "El Estado Parte debería velar por que en la formación judicial se tenga plenamente en cuenta la exigibilidad de los derechos enunciados en el Pacto, y adoptar medidas para que se conozca mejor la posibilidad de invocar sus disposiciones ante los tribunales". COMITÉ DE DERECHOS ECONÓMICOS, SOCIALES Y CULTURALES: Observaciones finales: Chile, E/C.12/1/Add.105, Ginebra, 1 de diciembre de 2004, párr. 29.

${ }^{43}$ De la misma opinión es, entre otros, PFEFFER URQUIAGA, EMILIO. "El recurso de protección y su eficacia en la tutela de los derechos constitucionales en Chile”. Estudios Constitucionales, 4(2): 23, 2006.
} 
AlEXY, Robert. Teoría de los Derechos Fundamentales. Madrid, Centro de Estudios Constitucionales, 2002.

Asamblea General De las Naciones Unidas: Declaración sobre Derecho al Desarrollo, Resolución 41/128, de 4 de diciembre de 1986, artículo 2.1.

BobBio, Norberto. Gurvitch y los derechos sociales. En su: El tiempo de los derechos, Madrid, Editorial Sistema, 1991, pp. 30 y 34.

BÖCKENFÖRDE, Ernst-Wolfgang. Escritos sobre derechos fundamentales. Baden-Baden, Nomos, 1993.

Cascajo Castro, José Luis. La tutela constitucional de los derechos sociales. Madrid, Centro de Estudios Constitucionales, 1988.

CEA EgAÑA, José Luis, Tratado de la Constitución de 1980: características generales: garantías constitucionales, Santiago, Chile, Editorial Jurídica de Chile, 1988.

Comisión De Estudios De la Nueva Constitución Política De La República, sesión 407, celebrada el miércoles 9 de agosto de 1978.

COMité De Derechos ECONÓmicos, Sociales Y Culturales: Observación general No 9 (1998), La aplicación interna del Pacto, E/C.12/1998/24, Ginebra, 3 de diciembre de 1998.

DE CASTRO CID, Benito. Los derechos económicos, sociales y culturales: análisis a la luz de la teoría general de los derechos humanos. León, Universidad de León, 1993.

FERnÁndez-Miranda CAMPOAmOR, Alfonso. El Estado social. Revista Española de Derecho Constitucional, 69(23), septiembre/diciembre 2003.

FERrajoli, Luigi. Democracia constitucional. En: COURTIS, Christian (compilador). Desde otra mirada. Buenos Aires, Eudeba, 2001.

Derechos y garantías. La ley del más débil. Madrid, Editorial Trotta, 1999.

García TORRes, Jesús y JimÉnEZ-Blanco, Antonio. Derechos fundamentales y relaciones entre particulares. Madrid, Civitas, 1986.

HAYEK, Friedrich. Derecho, Legislación y Libertad, Vol. 2, El espejismo de la justicia social. Madrid, Unión Editorial, 1979.

Holmes, Stephen y SunsteIn, Cass. The cost of rights: why liberty depends on taxes. New York, W. W. Norton, 1999. 
Infante, María Teresa. Los Tratados en el Derecho Interno Chileno: El Efecto de la Reforma Constitucional de 1989 visto por la jurisprudencia. Revista Chilena de Derecho, 23(2 y 3): 1996.

Kelsen, Hans. Teoría pura del derecho. México, Editorial Porrúa, 2005, p. 148.

Liebenberg, Sandra. Adjudicación de Derechos Sociales en la Constitución de Transformación Social de Sudáfrica. Anuario de Derechos Humanos, (2), 2006.

Loewenstein, Kart. Teoria de la Constitución. Barcelona, Ariel, 1976.

LUCAS VERDÚ, Pablo. Teoría general de las relaciones constitucionales. Madrid, Dykinson, 2000.

LuCIANI, Máximo. Sui diritti sociali. En: RombOLI, Roberto. La tutela dei diritti fondamentali alle Corti Costituzionali. G. Giapichelli, Torino, 1994.

MARTínez Estay, José. Jurisprudencia Constitucional Española sobre Derechos Sociales. Barcelona, Cedecs Editorial, 1997.

Nogueira, Humberto. Los Tratados Internacionales en el Ordenamiento Jurídico Chileno. Revista Chilena de Derecho, 23(2 y 3) 1996.

NowAK, Manfred. El Pacto Internacional de Derechos Civiles y Políticos. En: GómeZ IsA, Felipe (director). La protección internacional de los derechos humanos en los albores del siglo XXI. Bilbao, Universidad de Deusto, 2004.

ONIDA, Valerio. Eguaglianza e diritti sociali. Corte Costituzionale e principio di eguaglianza. Padova, CEDAM, 2001.

Pfeffer Urquiaga, Emilio. El recurso de protección y su eficacia en la tutela de los derechos constitucionales en Chile. Estudios Constitucionales, 4(2), 2006.

PISARELlo, Gerardo. Derechos sociales, democracia e inmigración en el constitucionalismo español: del originalismo a una interpretación sistemática evolutiva. En: AÑON ROIG, María José (ed.). La universalidad de los derechos sociales: el reto de la inmigración. Valencia, Tirant Lo Blanch, 2004.

Los derechos sociales y sus garantías. Madrid, Editorial Trotta, 2007.

PRIETO SANCHÍS, Luis. Los derechos sociales y el principio de igualdad sustancial. En: AÑON ROIG, María José (ed.). La universalidad de los derechos sociales: el reto de la inmigración. Valencia, Tirant Lo Blanch, 2004. 
RAWLS, John. A Theory of Justice (revised edition). Massachussets, Cambridge, The Belknapp Press of Harvard University Press, 1999.

Ruiz Tagle, Pablo y Correa, Sofía, El Derecho a una Educación de Calidad. Anuario de Derechos Humanos, (3), 2007.

Soto Kloss, Eduardo. El Recurso de Protección. Santiago, Chile, Editorial Jurídica de Chile. 